\title{
Uniaxial deformation of open-cell aluminum foam: the role of internal damage
}

\author{
C. San Marchi *, J.-F. Despois, A. Mortensen \\ Laboratory for Mechanical Metallurgy, Institute of Materials, Swiss Federal Institute of Technology in Lausanne (EPFL), \\ CH-1015 Lausanne, Switzerland
}

Received 1 December 2003; received in revised form 2 February 2004; accepted 24 February 2004 Available online 8 April 2004

\begin{abstract}
Internal damage accumulation is measured and shown to play a role in the mechanical response of replicated pure $\mathrm{Al}$ and $\mathrm{Al}-$ 12Si open-cell foams. This internal damage is quantified by measuring the reduction in the foam's stiffness with strain. The brittle Si second phase fractures during deformation of $\mathrm{Al}-12 \mathrm{Si}$ foam, resulting in damage accumulation rates an order of magnitude greater than for pure Al foam. Elementary damage mechanics is used to relate the measured rate of damage accumulation to the foam's tensile failure strain. The analysis and experimental results highlight in particular the strong embrittling influence of brittle second phases within the foam, such as $\mathrm{Si}$.
\end{abstract}

(C) 2004 Acta Materialia Inc. Published by Elsevier Ltd. All rights reserved.

Keywords: Foams; Mechanical properties; Elastic behavior; Mechanical properties: ductility; Aluminum; Damage

\section{Introduction}

Metallic foams have unique properties that make them useful in a number of potential applications including filtering, heat exchange, and energy absorption $[1,2]$. For energy absorption, the compressive properties of the foam are of primary importance; metallic foams have therefore been extensively studied using compression tests [2-4]. The tensile behavior of metallic foams, on the other hand, has been studied somewhat less systematically. One reason may be that in tension metallic foams tend to have low elongations to failure despite the inherent ductility typical of the metals they are made from. Many commercial aluminum foams are indeed reported to reach their peak stress at strains near $1 \%$ or less [5-9], while a few foams elongate, sometimes in specific orientations only, to strains of a few percent $[6,7,10,11]$.

\footnotetext{
${ }^{*}$ Corresponding author. Present address: Sandia National Laboratories, P.O. Box 969, MS-9402, Livermore, CA 94551-0969, USA. Tel.: +1-925-294-4880; fax: +1-925-294-3410.

E-mail address: cwsanma@sandia.gov (C. San Marchi).
}

The weakest link theory has been used to explain the small elongation to failure that is characteristic of metal foams: once the first structural element fails, the foam specimen as a whole fractures [6]. Metallic materials are, however, generally resistant to microstructural damage. In uniaxial tension, strain hardening works (together with strain-rate hardening if present) to compensate the destabilizing effect of internal damage. Extending this behavior to metallic foams implies that failure of a single structural element should not necessarily mean failure of the foam as a whole, provided the foam specimen is large enough in relation to the structural element size and provided the metal does indeed strain harden sufficiently.

Data from the literature for Al-based foams in tension show that the strain at peak stress is strongly influenced by the size of the tensile specimen if the pores are not substantially smaller than the gage section [10]. This is similar to testing of polycrystalline samples: well over 10 grains must run across the gage section of a tensile sample for meaningful testing of polycrystalline samples (with 10 grains or pores across the sample diameter, roughly one-third lie along the specimen surface) [12]. Metal foams with pores of sufficiently small 
size are therefore necessary when studying the tensile failure of these materials. Conventional foaming processes are not well-suited for this: closed cell pores are typically not less than $5 \mathrm{~mm}$ in average diameter, requiring tensile samples on the order of $10 \mathrm{~cm}$ in diameter. Metal foams with an average pore size of less than half of a millimeter, however, are readily produced by replication processing: more than 20 pores can then be found across a tensile sample with a gauge section that is $1 \mathrm{~cm}$ in diameter. This ensures that pores along the sample surface are in clear minority and that more than 100 pores are sampled across any given cross-section of the tensile bar. The influence of work hardening, which is pronounced in a metal such as pure aluminum, can then work to stabilize the foam against rupture of its weakest structural elements.

We provide in what follows a comparison of the compressive and tensile behavior of two metal foams produced by replication. One is of pure aluminum, the other of eutectic $\mathrm{Al}-12 \mathrm{Si}$. In bulk form, the latter alloy is well-known for its relatively brittle behavior, a result of rapid build-up of internal damage caused by fracture of the brittle silicon second phase [13-15]. It was chosen as a means of assessing the importance of the intrinsic ductility of the metal that constitutes the foam, an issue of interest by itself and also because many currently studied foams are made of a metal containing brittle second phases such as silicon carbide, intermetallics and oxides [16]. We show that pure aluminum foam can elongate to tensile strains of several percent, while the Al-12Si foam fractures at a significantly lower strain. We interpret these observations by drawing a correlation between the tensile elongation of metal foams and the rate of accumulation of internal damage, an approach previously shown to work well for metal-matrix composites.

\section{Experimental procedures}

Open-cell aluminum foams (also called "sponges") were produced by a three-step technique known as replication processing: (i) porous salt $(\mathrm{NaCl})$ patterns are prepared from powder, subsequently (ii) they are infiltrated with liquid aluminum, and finally (iii) the salt is removed by dissolution to produce a metallic foam. Details of the process and the structure of replicated aluminum foams can be found in [17-20].

In making the foams, two different melts were employed: high-purity aluminum $(99.99 \%$ from VAW, Grevenbroich, Germany) and $99.9 \%$ purity binary eutectic Al-Si alloy (Al-12.6Si from Alusuisse, Neuhausen, Switzerland). The density of the foams was measured from the mass knowing the dimensions of machined test specimens. The salt used in this study is the same as in [19], namely high-purity, spheroidal $\mathrm{NaCl}$ particles of an average diameter of $400 \mu \mathrm{m}$. All test specimens were machined from the $\mathrm{NaCl}-\mathrm{Al}$ composite castings prior to removal of the salt.

Compression testing was conducted using samples $20 \mathrm{~mm}$ in length and $20 \mathrm{~mm}$ in diameter, as in [19]. Tensile test specimens were round cylindrical bars with gauge dimensions of $80 \mathrm{~mm}$ in length and $14 \mathrm{~mm}$ in diameter. The ends of the machined tensile bars were then glued into aluminum cups that could be gripped in a screw-driven universal testing machine without damaging the foam.

An extensometer with a gauge length of $50 \mathrm{~mm}$ was used to measure deformation in tension at a nominal strain rate of $10^{-4} \mathrm{~s}^{-1}$. For both tension and compression testing, the initial stiffness of the foam was determined after pre-straining the specimen to $0.2 \%$ strain and then unloading to $10 \%$ of the maximum load. We computed the stiffness from the maximum slope of the nominal engineering stress-strain curve upon reloading. Similar unloading-reloading cycles were repeated after specific strain increments and the same procedure was used to monitor the evolution of the stiffness as a function of strain. For all measurements reported here, tension is defined as positive and compression as negative for both stress and strain. The microstructures of the as-cast foam and tested specimens were observed using standard scanning electron microscopy.

\section{Results}

\subsection{Microstructure}

The inner structure or architecture of the foam is uniform, reflecting the "replicated" negative of a packed bed of slightly sintered, nearly spherical, equiaxed particles, Fig. 1. This structure can be idealized as a random

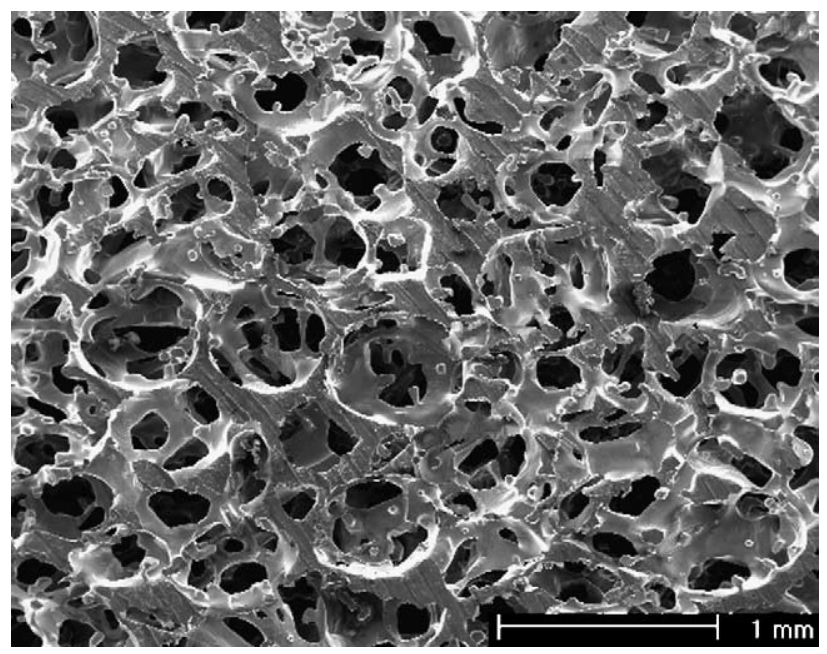

Fig. 1. Structure of aluminum foam produced by infiltrating a packed bed of uniform salt grains (relative density of the foam $=0.20$ ). 
array of short struts generally joined four at a time at each node.

Clear microstructural differences appear after deformation between the pure $\mathrm{Al}$ and the alloy foams. Individual structural elements of pure Al foams, called struts, are very ductile: after compression, struts are highly deformed in bending, Fig. 2. When deformed in tension, broken struts of pure $\mathrm{Al}$ neck down to a point, Fig. 3.

In contrast, individual struts in the $\mathrm{Al}-12 \mathrm{Si}$ foams accumulate internal damage in the form of fracture of the Si second phase, as shown in Fig. 4 for compression. This microstructural damage causes relatively brittle fracture of the individual struts in tension. Fractured struts thus show relatively little necking, with hard and brittle $\mathrm{Si}$ second-phase particles at the bottom of the dimples that characterize their tensile fracture surface, Fig. 5.

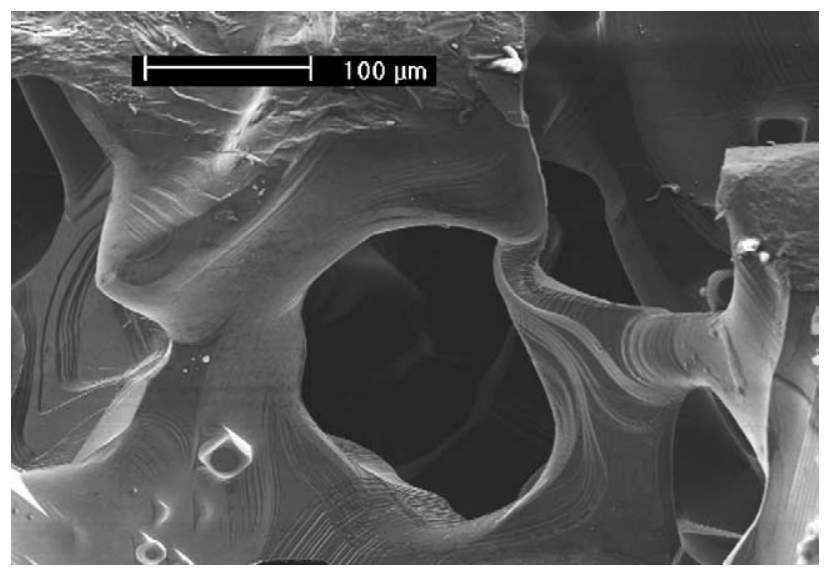

Fig. 2. Structure near the surface of compressed pure $\mathrm{Al}$ foam showing deformed structural elements (relative density of the foam $=0.20$ ).

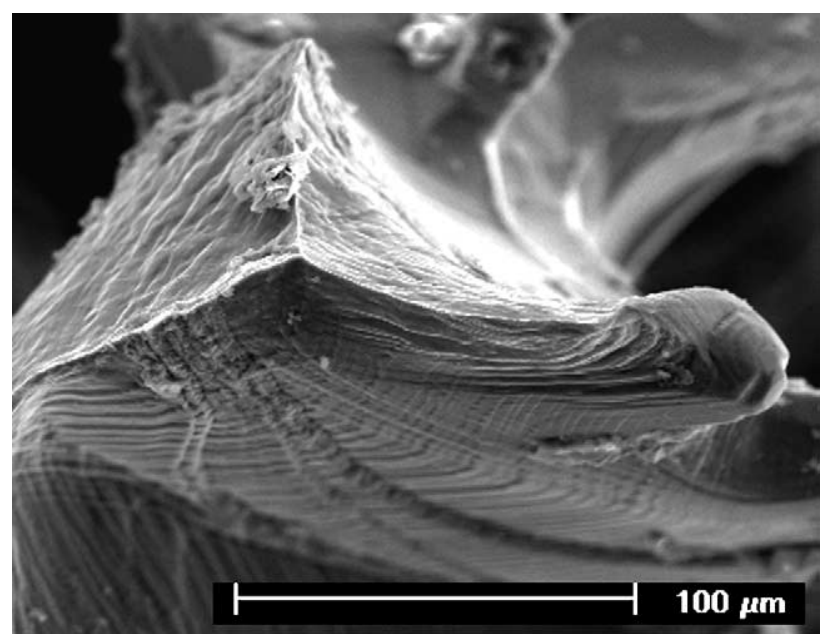

Fig. 3. Tensile fracture surface of pure $\mathrm{Al}$ foam, showing a strut that has necked to a point (sample A4).

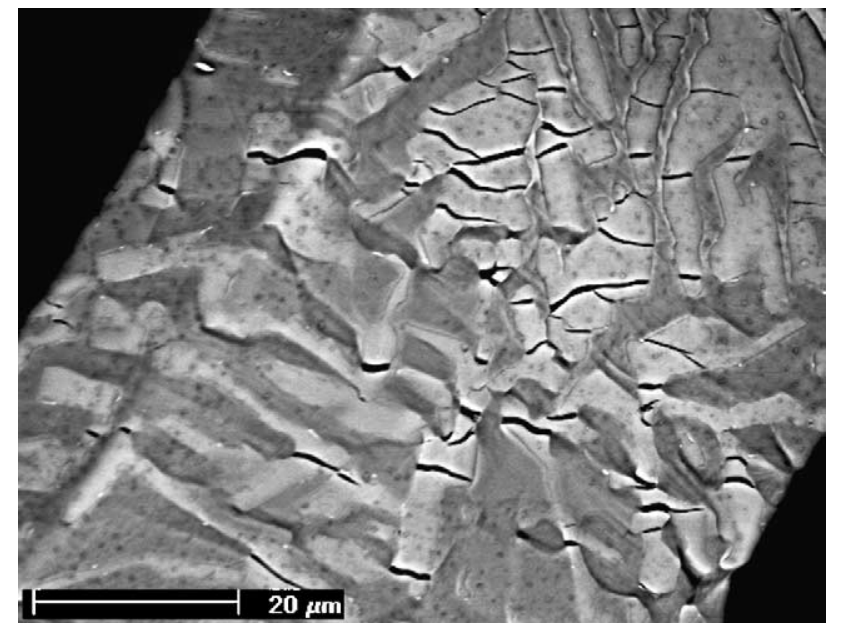

Fig. 4. Surface of a strut within a eutectic Al-12Si foam deformed in compression, shown at high magnification to display "microfracture" of the $\mathrm{Si}$ second phase in the $\mathrm{Al}-12 \mathrm{Si}$ alloy that constitutes the foam (relative density of the foam $=0.30$ ).
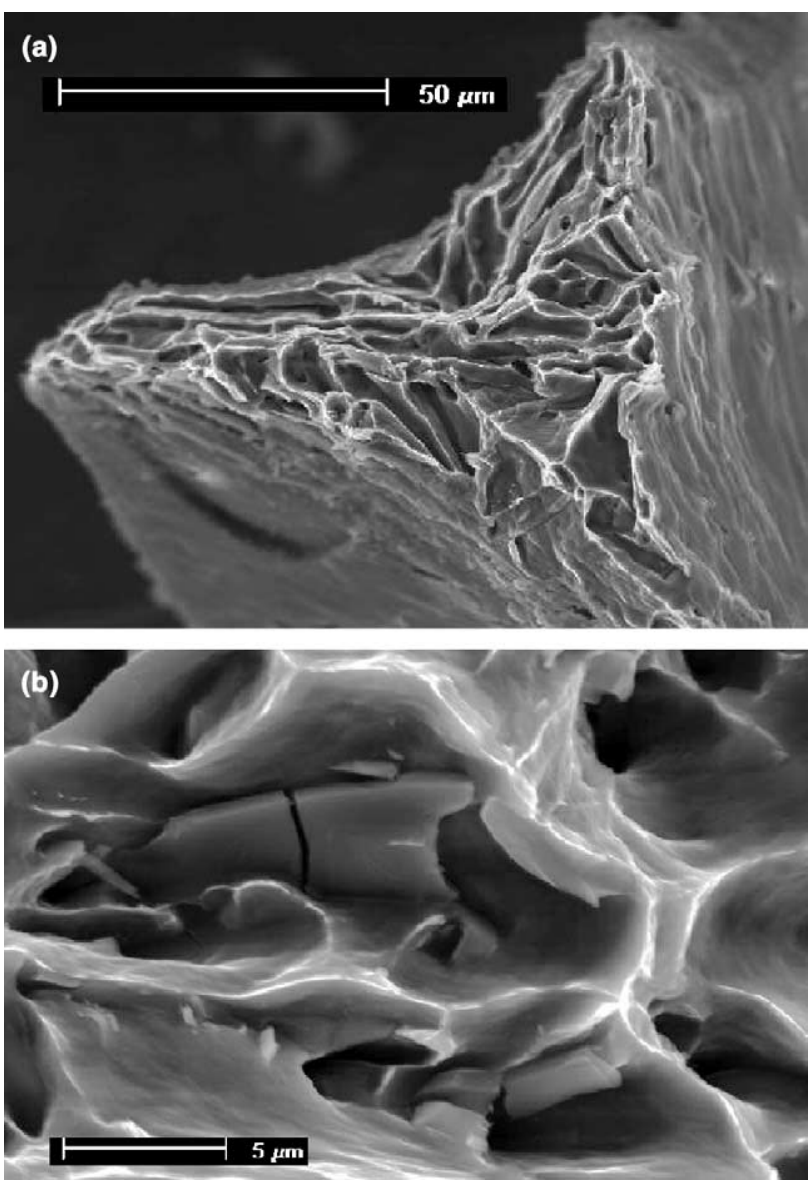

Fig. 5. Tensile fracture surface of Al-12Si foam: (a) the cross-section of a strut that has fractured without substantial necking; (b) fracture of the silicon phase and the dimples in the surrounding aluminum-matrix (sample S1). 


\subsection{Compressive deformation}

Representative nominal (engineering) stress-strain curves are plotted in Fig. 6 for the pure $\mathrm{Al}$ and $\mathrm{Al}-12 \mathrm{Si}$ foams in compression; the compressive behavior of pure Al foam was reported in detail in [19]. The flow stress of the Al-12Si foam is about four times higher than the pure $\mathrm{Al}$ foam, while the relative (stress-normalized) rate of work hardening is lower. As with pure Al, the deformation curves for $\mathrm{Al}-12 \mathrm{Si}$ foams in compression do not show the idealized plateau stress typically displayed by commercial closed-pore aluminum-based foam [2-4].

The evolution of the elastic stiffness during compression is plotted in Fig. 7 for several pure Al and Al12Si foams. As described in [19], the elastic stiffness of pure Al foam decreases with compressive deformation up to a strain of about $-15 \%$, after which it increases. The relative stiffness of the alloy foam also decreases in compression, but at a greater rate than observed for the pure $\mathrm{Al}$ foam, Fig. 7. Both pure $\mathrm{Al}$ and $\mathrm{Al}-12 \mathrm{Si}$ foam display a minimum in stiffness; this minimum occurs at

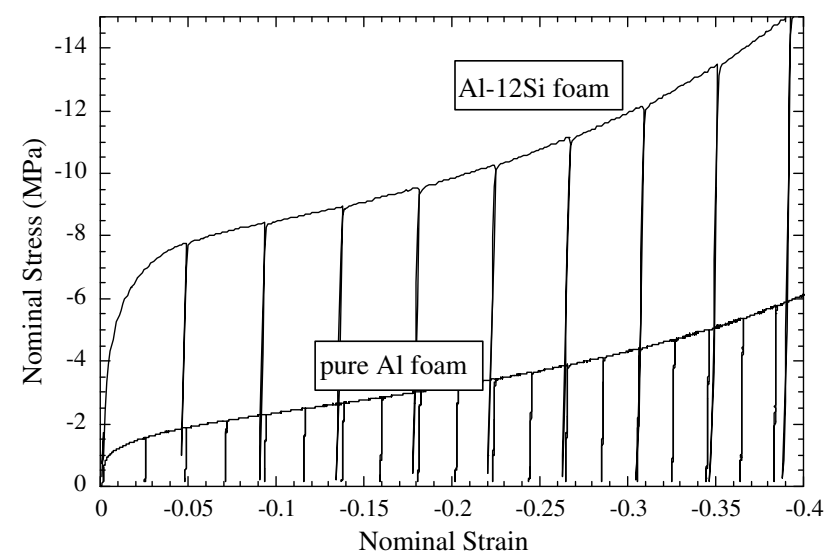

Fig. 6. Nominal compressive stress-strain curves for pure Al foam (relative density $=0.26$ ) and $\mathrm{Al}-12 \mathrm{Si}$ foam (relative density $=0.27$ ).

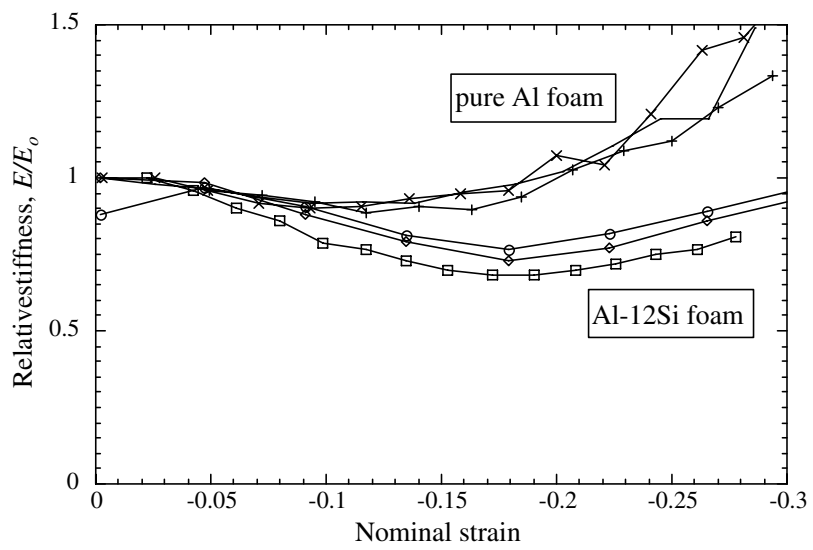

Fig. 7. Evolution of elastic stiffness during compressive deformation of several pure $\mathrm{Al}$ foams and $\mathrm{Al}-12 \mathrm{Si}$ foams. higher (more compressive) strains in the $\mathrm{Al}-12 \mathrm{Si}$ foam than the pure $\mathrm{Al}$ foam.

\subsection{Tensile deformation}

The tensile behaviors of pure $\mathrm{Al}$ and $\mathrm{Al}-12 \mathrm{Si}$ foams are contrasted in Fig. 8. As in compression, the Al-12Si foam displays a tensile flow stress and an ultimate tensile strength that are about four times higher than for the pure $\mathrm{Al}$ foam. The Al-12Si foam, on the other hand, is more brittle: the elongation to failure $e_{\mathrm{f}}$, defined as the strain at peak load, is between $1 \%$ and $2 \%$ for the $\mathrm{Al}-$ 12Si foams. By contrast, the pure Al foams display $e_{\mathrm{f}}>5 \%$, Fig. 8 and Table 1 .

Tensile failure in both foams is not distinguished by the abrupt formation of two distinct fracture surfaces; rather the load drops rapidly after the peak is reached while some struts may hold the two ends together to significantly higher strains. Failure, moreover, is not necessarily restricted to one plane as would be expected by the weakest link theory. In some cases, after the peak load is reached, two apparent cracks or fracture planes can be distinguished, held together by a network of deformed struts.

The measured elastic stiffness of the foam is plotted in Fig. 9 as a function of nominal strain for a pure $\mathrm{Al}$ and an $\mathrm{Al}-12 \mathrm{Si}$ foam in tension. The stiffness of both foams decreases at the onset of tensile deformation. The rate of stiffness loss in the Al-12Si foam is significantly greater than for the pure $\mathrm{Al}$ foam. Approximating the evolution of the elastic stiffness $E$ with nominal strain $e$ as a straight line (between $e=0$ and $e$ at peak load), an average rate of normalized stiffness decrease $\alpha$ can be defined as

$\alpha=\frac{-1}{E_{0}} \frac{\mathrm{d} E}{\mathrm{~d} e}$,

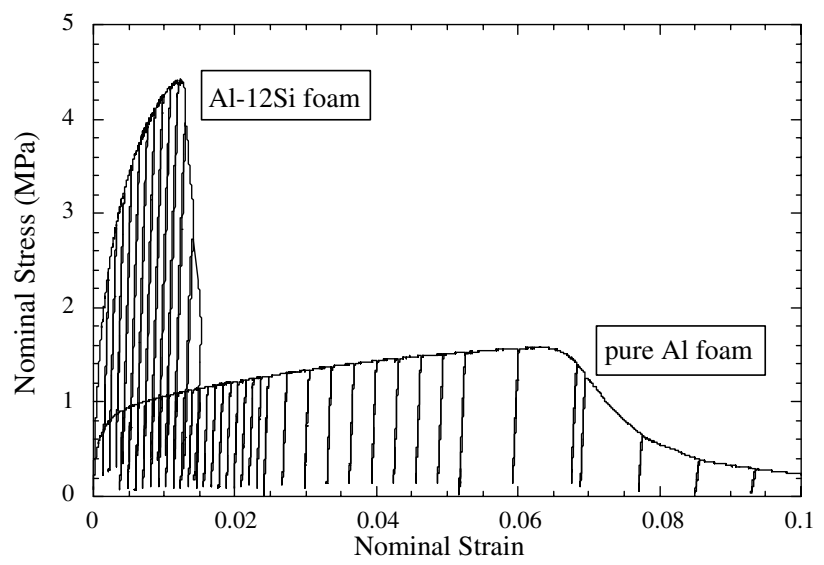

Fig. 8. Nominal tensile stress-strain curves for pure $\mathrm{Al}$ foam (sample A4) and $\mathrm{Al}-12 \mathrm{Si}$ foam (sample S1). 
Table 1

Density, damage and failure strain of aluminum foams tested in tension; $n=0.26$ for predictions of failure strain, Eq. (7)

\begin{tabular}{lllll}
\hline Sample & Relative density $(\%)$ & Damage parameter, $\alpha$ & Strain at peak stress, $e_{\mathrm{f}}(\%)$ & Predicted $e_{\mathrm{f}}$ from Eq. $(7)(\%)$ \\
\hline A1 (Pure Al) & 27 & 0.7 & 7.3 & 10.8 \\
A2 (Pure Al) & 27 & 1 & 7.4 & 9.9 \\
A3 (Pure Al) & 21 & 2.2 & 5.1 & 6.5 \\
A4 (Pure Al) & 26 & 1.3 & 6.5 & 9.0 \\
S1 (Al-12Si) & 32 & 10.4 & 1.3 & 1.9 \\
S2 (Al-12Si) & 20 & 11.9 & 1.1 & 1.6 \\
\hline
\end{tabular}

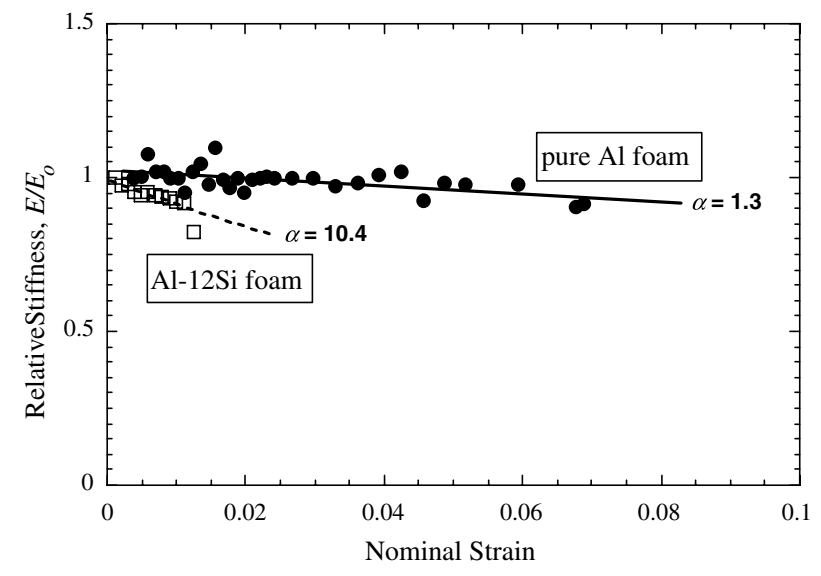

Fig. 9. Evolution of elastic stiffness during tensile deformation for pure Al foam (sample A4) and Al-12Si foam (sample S1); the lines show the linear fit to the data.

where $E_{0}$ is the elastic stiffness of the undeformed foam. Values of $\alpha$ are significantly higher for the $\mathrm{Al}-12 \mathrm{Si}$ foams than for pure $\mathrm{Al}$ foams, Table 1.

\section{Discussion}

The replicated open-cell foams of this work differ in their general mechanical behavior from closed-cell aluminum foams produced using conventional foaming processes and studied generally in the literature. In particular, studies on closed-cell foams in the literature show that plastic compressive deformation is triggered by internal defects and is localized in a band of cells while the other regions of the foam remain elastic [21,22]. After the collapse of a discrete band of cells, a subsequent band deforms and collapses until all the undeformed cells are consumed. As each band has approximately the same strength, the compressive strength of the foam remains relatively constant until virtually all the cells have collapsed at which point the stress in the foam rises rapidly. The strain at which this sudden rise in stress is observed is called the densification strain and is directly related to the initial density of the foam [2,3]. This compressive response differs markedly from the response of replicated pure Al foams studied here, and described in [19]. The present replicated foams deform uniformly (i.e., they display no collapse bands in compression) and display hardening (a rising stress-strain curve) over the entire range of compressive strains. Consequently, a distinct densification strain is not easily defined. As shown in [19], two mechanisms of work hardening exist in the present foams: (i) the intrinsic work hardening caused by deformation of the metal making the foam and (ii) another mechanism, the effect of which becomes noticeable on the stress-strain curve at compressive strains greater than $-10 \%$ to $-15 \%$. This second mechanism causes a minimum in the work hardening rate and in the instantaneous stiffness as a function of compressive strain (Fig. 7). The precise nature of this second work hardening mechanism is at present not identified; however, as argued in [19], evidence to date suggests that it involves the impingement of struts on one another, i.e., the formation of new solid material contacts across the open pores of the foam.

\subsection{Pure Al foam}

At (compressive) strains between about $-1 \%$ and $-10 \%$ it was demonstrated in [19], by experiment and using a simple beam model, that the nominal (engineering) stressstrain response is described by a power law relationship:

$\tilde{S}=k e^{n}$,

where $\tilde{S}$ is the nominal stress (in the absence of damage), $k$ is a constant and $n$ is the strain hardening coefficient of the material that constitutes the foam. That study also demonstrated that the evolution of the relative stiffness with nominal strain $e$ (compressive strain defined as negative) could be described in the same strain range by

$\frac{\tilde{E}}{E_{0}}=\frac{1}{(1+e)(1-2 e)}$,

where $\tilde{E}$ is the elastic stiffness (in the absence of internal damage). This relationship can be derived assuming that permanent deformation occurs mainly by the formation of plastic hinges at the junctions between the struts of aluminum that make up the foam structure [19].

For pure $\mathrm{Al}$ foams deformed in compression, there is no evidence of microstructural changes that would affect the stiffness of the metal, Fig. 2. The good correlation of the models described above with experimental data [19] 
further supports the conclusion that pure $\mathrm{Al}$ foam deforms without internal damage if we define internal damage as microstructural changes at the strut-level that are induced by deformation and that reduce the axial stiffness of individual struts. The stiffness of the foam is thus apparently changed only by the reorientation of the struts that accompanies bending.

In tension, then, Eq. (3) predicts an increase in the stiffness of the foam. The experimental data, however, display a decrease in stiffness, nearly from the onset of tensile deformation, Fig. 9. This indicates that, unlike in compression, there is internal damage accumulation in pure $\mathrm{Al}$ foams during tensile deformation. This internal damage appears in the microscope as localized necking and rupture of individual struts, Fig. 3. Clearly, this must contribute to the tensile failure of the foam.

\subsection{Al-12Si foam}

In the absence of internal damage, it is expected that the Al-12Si foam will deform with approximately the same $n$ as pure Al foam. Indeed, aluminum-silicon alloys consist of a single-phase (and relatively pure) aluminum matrix containing hard, brittle silicon particles that essentially do not deform. As well-known from composite theory, such a two-phase material deforms, after a small transient and in the absence of damage, with the same power law and exponent $n$ as its matrix [23]. The power law exponent $n$ for $\mathrm{Al}-12 \mathrm{Si}$ foam, however, is significantly less than for pure Al. This is because it includes the effect of damage: the apparent $n$ is $\sim 0.15$ for $\mathrm{Al}-12 \mathrm{Si}$ foam compared to an apparent $n$ of $\sim 0.26$ for pure $\mathrm{Al}$ foam. As mentioned, fracture of the $\mathrm{Si}$ phase is evident in $\mathrm{Al}-12 \mathrm{Si}$ foam deformed in both compression and tension, Figs. 4 and 5: this is evidently the mechanism of damage accumulation in this foam during compression. Fracture of the hard, brittle Si phase in Al-Si alloys and their consequences are well documented [13-15]: the rate of work hardening (and hence $n$ ) as well as the elongation to failure are reduced as a consequence of this internal damage. Similar behavior is observed for pure aluminum-matrix composites reinforced with hard, brittle particles such as alumina and boron carbide [24,25].

Stiffness is similarly affected by internal damage accumulation: the rate of stiffness loss in compression is greater in the $\mathrm{Al}-12 \mathrm{Si}$ foam compared to the nondamaging pure $\mathrm{Al}$ foam. Damage, moreover, delays the recovery of stiffness, i.e., the minimum in the stiffness evolution occurs at higher compressive strains in Al12Si foam, Fig. 7.

In tension, the rate of stiffness loss is nearly an order of magnitude greater for $\mathrm{Al}-12 \mathrm{Si}$ foam relative to pure Al foam, as evident in the evolution of stiffness as a function of strain in Fig. 9 and the values of $\alpha$ in Table 1 . This is clearly also a result of fracture of the brittle silicon phase, which reduces the load-bearing capacity of the struts and induces tensile failure without substantial necking of the individual struts, contrary to observations for pure Al, Fig. 5.

\subsection{Internal damage and tensile failure}

The measured change in stiffness of these foams can be related to their strain at the onset of tensile instability by employing elementary assumptions from continuum damage mechanics. Lemaitre [26] postulates that the relative reduction in modulus can be taken to be equal to the relative reduction in flow stress in a damaged elastoplastic material. The use of this assumption has recently been shown to provide a useful tool for the prediction of failure strains of metal-ceramic composites if the rate of damage accumulation is known [24,25]. We therefore examine whether it can be used to predict the tensile elongation of the present open-pore aluminum foams.

A few changes must be brought to the derivation in $[24,25]$ because in the foam, due to bending of struts, the stiffness (or modulus) changes even in the absence of damage. The relative rate of decrease of the elastic modulus is therefore not an adequate measure of damage. Rather, internal damage in a foam must be measured by the difference between the instantaneous modulus and the modulus predicted by Eq. (3). In addition, for foams it is simpler to work with nominal stress and strain rather than true values, because stress and stiffness are most conveniently computed based on the assumption of constant cross-section since the lateral strains are nearly zero (and not controlled by volume constancy).

We therefore begin by writing Lemaitre's relationship in terms of the measured nominal flow stress $\mathrm{S}$ :

$\frac{S}{\tilde{S}}=\frac{E}{\tilde{E}}$,

where $E$ is the elastic stiffness of the foam, and the tilde $(\tilde{S}$ and $\tilde{E}$ ) refers to the values that would be displayed by the foam at the same strain in the absence of internal damage. The modulus-based damage parameter $D_{E}$, frequently used in the context of damage-mechanics, is thus defined as $D_{E}=1-(E / \tilde{E})$.

It was shown in [27] that, regardless of the accumulation of damage and ensuing lack of volume conservation, the onset of tensile instability in a damaging (strain-rate insensitive) material coincides with the maximum in the engineering stress-strain curve:

$\mathrm{d} S / \mathrm{d} e=0$. 
Defining the failure strain $e_{\mathrm{f}}$ as the (nominal) strain at this instability (i.e., at peak load), $e_{\mathrm{f}}$ can be predicted from material parameters and damage by inserting Eqs. (2)-(4) into Eq. (5):

$e_{\mathrm{f}}=\frac{n}{\delta+\frac{2}{1-2 e_{\mathrm{f}}}-\frac{1}{1+e_{\mathrm{f}}}}$,

where $\delta=-\mathrm{d}(\ln E) / \mathrm{d} e$. Assuming the stiffness decreases linearly with strain and thus using Eq. (1) to introduce parameter $\alpha$, the failure strain can be expressed as

$e_{\mathrm{f}}=\frac{n}{\frac{\alpha}{1-\alpha e_{\mathrm{f}}}+\frac{2}{1-2 e_{\mathrm{f}}}-\frac{1}{1+e_{\mathrm{f}}}}$.

For $e_{\mathrm{f}} \ll 1$, as satisfied by the $\mathrm{Al}-12 \mathrm{Si}$ foams, Eq. (7) reduces to

$e_{\mathrm{f}} \approx n /(\alpha+1)$,

and shows that the tensile failure in foams can be greatly reduced even by moderate rates of accumulation of internal damage.

Failure strains predicted from Eq. (7) for foams tested in this study are given in Table 1 using $n=0.26$ for both pure $\mathrm{Al}$ and $\mathrm{Al}-12 \mathrm{Si}$. Eq. (7) overestimates the measured failure strains somewhat but the derivation captures the observed difference in ductility between pure $\mathrm{Al}$ and $\mathrm{Al}-12 \mathrm{Si}$, showing the link that exists between damage accumulation and tensile ductility in these metal foams. In particular, this relationship shows that: (i) the limited tensile ductility obtained even with foam of very ductile metal (pure Al) is a consequence of internal damage and that (ii) the significant difference in ductility between the $\mathrm{Al}-12 \mathrm{Si}$ and the pure $\mathrm{Al}$ foam arises due to a difference in the rate of damage accumulation within the two different materials that make up these foams. This suggests that internal damage is probably a principal reason for the low tensile failure strains exhibited by nearly all metallic foam, many of which contain brittle second phases [5-9].

The microstructure of the metal that constitutes the foam is thus an important parameter in the mechanical performance of metal foams. Two-phase alloys or composites containing large brittle second phase constituents, which are often necessary for foaming of metals [16], are certainly undesirable if one aims to obtain a good balance between strength and tensile ductility in metal foams. Solid solution strengthening may provide just such a balance since the lack of second phases should result in resistance to internal damage comparable to pure Al but with a significantly higher flow stress. Compression data for $\mathrm{Al}-5 \mathrm{Mg}$ foam from [20] hint towards this possibility in tension. In any case, as shown here, damage accumulation can limit ductility of even the most ductile alloy foams under tension.

The predicted $e_{\mathrm{f}}$ exceeds the measured values by 30 $50 \%$. We propose two reasons for this systematic discrepancy. First, the value of $n$ used here $(0.26)$ may perhaps be too high for tension. A value of $n=0.20$ (exhibited by composites produced analogously with the same pure Al-matrix and tested in tension) may be more relevant for tensile deformation. This would imply that the apparent $n$ measured for pure Al foam in compression is higher than in tension. Such an effect could be a result of a small level of mutual strut impingement occurring during compressive deformation even at low strains [19]. Also, we have used for simplicity a value of $\alpha$ measured in each test as the slope of a single straight line fitted through all of the specimen's modulus data; however, there is no fundamental reason that the modulus should vary linearly with strain. Although it could indeed be argued that the rate of decrease of $E$ increases slightly with strain, particularly near failure, uncertainty in the data precludes the utility of further analysis (fitting anything but a straight line through the data would require a level of subjectivity in the choice of $\alpha$; hence, a single value for $\alpha$ and the value of $n$ from previous work [19] were used here for simplicity).

In closing, we note that the density of the foam does not appear explicitly in any of the relations developed here. A similar result was obtained both theoretically and experimentally for the relative stiffness change during compressive deformation of pure Al foam [19]. The density should, however, affect the rate of damage (and hence parameter $\alpha$ ) since the shape, and therefore the failure strain, of individual struts constituting the foam change as the density of the foam changes: lower density foams have thinner struts that are more susceptible to damage. The tendencies emerging from this study (see Table 1) combined with the literature $[10,28]$ indicate that the tensile failure strain of foams does indeed tend to be somewhat greater for more dense foams. Therefore, although it does not appear explicitly in Eq. (7), the foam density should indeed influence the foam ductility and does so through the parameter $\alpha$, which is expected to decrease as the density increases.

\section{Conclusion}

Pure $\mathrm{Al}$ and $\mathrm{Al}-12 \mathrm{Si}$ open-cell foams display evidence of internal damage accumulation during tensile deformation; microstructural damage is also apparent during compression of Al-12Si foam, although not for pure Al foam. Such damage takes the form of: (i) fracture of the brittle $\mathrm{Si}$ phase in the $\mathrm{Al}-12 \mathrm{Si}$ foam and (ii) tensile failure of individual struts in both foam materials.

A simple damage mechanics approach, previously found effective for ceramic-aluminum composites, provides a link between damage (as measured by the instantaneous stiffness of the foam) and the strain at which tensile instability sets in, causing failure of the foam. It is 
shown that internal damage explains the relatively low tensile failure strains associated with aluminum alloy foams compared to the bulk material from which they are made.

\section{Acknowledgements}

This work was funded by the Swiss National Science Foundation, Project No. 21-58839.99, and by core funding of the Laboratory for Mechanical Metallurgy at EPFL. We also acknowledge the contribution of David Curran, who conducted some of the tensile tests during a summer stay at EPFL, and give thanks to Dr. Marianna Kouzeli, who provided many insightful comments at various stages of this work.

\section{References}

[1] Davies GJ, Zhen S. J Mater Sci 1983;18:1899.

[2] Ashby MF, Evans A, Fleck NA, Gibson LJ, Hutchinson JW, Wadley HNG. Metal foams: a design guide. Boston, MA: Butterworth Heinemann; 2000.

[3] Gibson LJ, Ashby MF. Cellular solids - structure and properties. 2nd ed. Cambridge, UK: Cambridge University Press; 1997.

[4] Gibson LJ. Annu Rev Mater Sci 2000;30:191.

[5] Gradinger R, Simancik F, Degischer HP. Determination of mechanical properties of foamed metals. In: Felber S, Varga T, Zeman JL, editors. International Conference on Welding Technology, Materials and Materials Testing, Fracture Mechanics and Quality Management. Vienna, Austria: Chytra Druck \& Verlag GmbH; 1997. p. 701.

[6] McCullough KYG, Fleck NA, Ashby MF. Acta Mater 1999;47:2323.

[7] Andrews E, Sanders W, Gibson LJ. Mater Sci Eng A 1999;270:113.

[8] Markaki AE, Clyne TW. Acta Mater 2001;49:1677.

[9] Olurin OB, Fleck NA, Ashby MF. Mater Sci Eng A 2000;291:136.
[10] Von Hagen H, Bleck W. Compressive, tensile and shear testing of melt-foamed aluminium. In: Schwartz DS, Shih DH, Evans AG, Wadley HG, editors. Porous and Cellular Materials for Structural Applications Materials Research Society Symposium Proceedings, vol. 521. Warrendale, PA: Materials Research Society; 1998. p. 59.

[11] Motz C, Pippan R. Acta Mater 2001;49:2463.

[12] Kocks UF. Metall Trans 1970;1:1121.

[13] Hunt W, Brockenbrough JR, Magnusen PE. Scripta Metall 1991;25:15.

[14] Kiser MT, Zok FW, Wilkinson DS. Acta Mater 1996;44:3465.

[15] Poole WJ, Dowdle EJ. Scripta Mater 1998;39:1281.

[16] Banhart J. Prog Mater Sci 2001;46:559.

[17] Polonsky L, Lipson S, Markus H. Modern Castings 1961;39: 57.

[18] San Marchi C, Despois JF, Mortensen A. Fabrication and compressive response of open-cell aluminum foams with submillimeter pores. In: Clyne TW, Simancik F, editors. Metal matrix composites and metallic foams, Euromat 99, vol. 5. Munich, Germany: DGM/Wiley-VCH; 1999. p. 34.

[19] San Marchi C, Mortensen A. Acta Mater 2001;49:3959.

[20] San Marchi C, Mortensen A. Infiltration and replication process for producing metal sponges. In: Degischer HP, Kriszt B, editors. Handbook of celllular metals: production, processing, applications. New York: Wiley-VCH Verlag; 2002.

[21] Bart-Smith H, Bastawros A-F, Mumm DR, Evans AG, Sypeck DJ, Wadley HNG. Acta Mater 1998;46:3583.

[22] Bastawros A-F, Bart-Smith H, Evans AG. J Mech Phys Solids 2000;48:301.

[23] Bao G, Hutchinson JW, McMeeking RM. Acta Metall Mater 1991;39:1871.

[24] Kouzeli M, Weber L, San Marchi C, Mortensen A. Acta Mater 2001;49:3699.

[25] Kouzeli M, San Marchi C, Mortensen A. Mater Sci Eng A 2002;337:264.

[26] Lemaitre J. A course on damage mechanics. Heidelberg, Germany: Springer; 1992.

[27] Weber L, Kouzeli M, SanMarchi C, Mortensen A. Scripta Mater 1999;41:549.

[28] Despois J-F, Conde Y, San Marchi C, Mortensen A. Tensile behavior of replicated aluminium foams. In: Banhart J, Fleck NA, Mortensen A, editors. Proceedings of the Metfoam 2003 Conference; Berlin, June 2003. Bremen (Germany): MIT Verlag; 2003. p. 375 . 